\title{
Postmenopausal osteoporosis: some practical issues
}

\author{
Sarath Lekamwasam ${ }^{1}$ \\ Sri Lanka Journal of Diabetes Endocrinology and Metabolism 2011; 1: 18-21
}

\section{Burden of the disease}

Osteoporosis-related fractures are a major economic concern in many developed as well as less developed countries. Osteoporosis affects estimated 75 million people in Japan, Europe and USA (1). Currently, approximately 1.6 million hip fractures occur annually worldwide and this figure is estimated to increase gradually and reach 4.5-6.3 million by $2050(2,3)$. According to the Asian osteoporosis audit published by the International Osteoporosis Foundation, the incidence of hip fractures in Sri Lanka will rise from the 2006 figure of nearly 2700 to 4900 in 2020 and 6900 in 2041. These were based on average population projections and according to the growth rate of elderly sector of the population these figures could become higher (4).

Although a fracture at any site could be attributed to osteoporosis, fractures of hip and vertebrae are the classical fragility fractures. Each fracture type has its own patient characteristics and morbidity and mortality pattern. Hip facture is the most sinister osteoporosis-related fracture owing to the health care cost involved and associated mortality and morbidity. It is estimated that nearly $20-25 \%$ hip fracture survivors die within the first year (5). The increased mortality could persist up to five years after a hip fracture. Hip fracture has profound effects on physical independence. Nearly $40 \%$ of hip fracture survivors have walking disability while $60 \%$ require assistance to maintain day to day physical activities (6). Furthermore, one third of hip fracture patients are totally physically dependent or require nursing home placement at one year following fracture (7).

Vertebral fracture has its own characteristics yet different from hip fracture. Only one third of vertebral fractures are symptomatic (8). Therefore most of the vertebral fractures are detected as an incidental finding. Vertebral fractures are associated with acute and chronic backache, loss of mobility and functions. Further, vertebral fractures lead to more vertebral fractures and non-vertebral fractures in later years $(9,10)$.

Although considered an end-result of osteoporosis, forearm fractures behave different to fractures at other sites such as hip and vertebrae. Distal forearm fractures lack the classical exponential rise with advancing age (11) seen with typical osteoporosis-related fractures such as hip and vertebrae. Also they tend to occur in relatively young people (11). Although no increased mortality is seen following distal forearm fractures, increased incidence of pain and numbness of affected hand is reported.

\section{Geographical variation of osteoporosis prevalence and incidence of fractures}

Prevalence of osteoporosis and the incidence of related fractures have a marked geographical variation and the reasons for this variation are not well understood $(12,13)$. In defining osteoporosis in 1994, the WHO working group opted for the T-score cut-off value of -2.5 as it demarcated nearly $30 \%$ of women over 50 years as having the disease and this approximated to the proportion of population having lifetime fracture risk (14). Subsequent studies applying this cut-off value, however, demonstrated a wide variation in postmenopausal osteoporosis prevalence. This could partly be due to variations in the composition of study samples, inclusion and exclusion criteria, skeletal sites included in the analysis etc. In 2002, Holt et al demonstrated a substantial difference in the prevalence of osteoporosis between USA and UK women older than 50 years (15). Among Thai postmenopausal women, osteoporosis prevalence varies between women of more than five years since menopause and women of less than five years since menopause (16). Among Chinese women between 20-89 years, the prevalence of osteoporosis varies from $15 \%$ to $28 \%$ between hip and lumbar spine (17). A previous study in Sri Lanka indicated that nearly $48 \%$ of women above 50 years are likely to suffer from osteoporosis. This analysis was based on an extrapolation of a subgroup analysis and used bone mineral density in an appendicular skeleton (18). Further community-based studies are required in Sri Lanka to confirm the finding of this solitary study.

Table. T-score thresholds for categorization of postmenopausal women

$\begin{array}{ll}\text { Category } & \text { T-Score } \\ \text { Normal } & \text { Above }-1.0 \\ \text { Osteopenia } & \text { Between }-1.0 \text { and }-2.5 \\ \text { Osteoporosis } & -2.5 \text { or lower } \\ \begin{array}{l}\text { Established osteoporosis } \\ \text { fracture }\end{array} & -2.5 \text { or lower }+ \text { fragility }\end{array}$


Apart from osteoporosis prevalence, the incidence of fragility fracture also varies. While the highest fracture incidence is reported from Scandinavian countries, a marked variation in hip fracture incidence was seen across Europe (12). Furthermore, there is a difference in the hip fracture incidence between the northern and southern regions of Europe. The incidence of hip fractures reported in Asian countries also varies, widely. Although many previous reports indicated a lower incidence of hip fractures $(3,19)$, recent studies have shown a clear secular change in the fracture incidence (20). Most of the studies indicate an increasing trend of hip fractures in Asian countries (20). While this could be a real increase due to factors such as rapid urbanization and sedentary life-style of modern city dwellers, improved case reporting and easy access to health care may also have played a role.

\section{Problems faced by clinicians in Sri Lanka}

Lack of awareness of the disease is a major problem in certain parts of Sri Lanka. Awareness of osteoporosis is high in urban areas but the accuracy of the information they possess is highly questionable. Many have learned about the disease from printed and electronic media but the information given in these appear to be bias towards certain aspects related to the diaseasedisease. Regular education programmes are being conducted by Osteoporosis Sri Lanka focusing opinion leaders in the health care system who could take the message to community level.

Limited availability of screening facilities for low bone mass is a major problem worldwide and the situation in Asian countries is worse. According to the recent Asian Osteoporosis Audit compiled by the International Osteoporosis Foundation, the availability of Dual Energy Absorptiometry (DXA) in most of the Asian countries is a major concern (4). The situation cannot be expected to improve in the near future and clinicians will have to find an alternative ways to detect women with osteoporosis.

Local Bone Mineral Density (BMD) reference data is essential for accurate categorization of women into the WHO diagnostic categories (Table). Although NHANES BMD reference data are being used widely in the USA and European countries, the applicability of this reference data to populations outside these two regions is highly questionable. Previous studies have shown a wide variation of osteoporosis prevalence when two reference data sets were used on the same patient population $(21,22)$. Although it is a daunting task, every country should be encouraged to develop their local BMD reference data.

The use of WHO T-score cut-off values introduced in 1994 to identify women at high risk of fracture has major limitations. Although BMD is the most quantifiable risk factor of future fracture, there are many other clinical risk factors of fractures. Furthermore, according to previous studies most of osteoporosis-related fractures occurred in women with osteopenia. As a solution to this issue, WHO recently introduced the FRAX algorithm to help clinicians in therapeutic decision making. FRAX is a webbased calculator (Figure) which, apart from BMD, accommodates multiple clinical risk factors in estimating fracture risk (http://www.shef.ac.uk/FRAX). The clinical risk factors included in the FRAX model are age, gender, weight, height, past history of fracture, parental history of fracture, use of glucocorticoids, smoking habits, alcohol consumption, secondary causes of bone loss and rheumatoid arthritis. The output displays the probability of major osteoporotic as well as hip fractures during the next 10 years. Since its introduction, FRAX has undergone many alterations and many country-specific FRAX models have been developed.

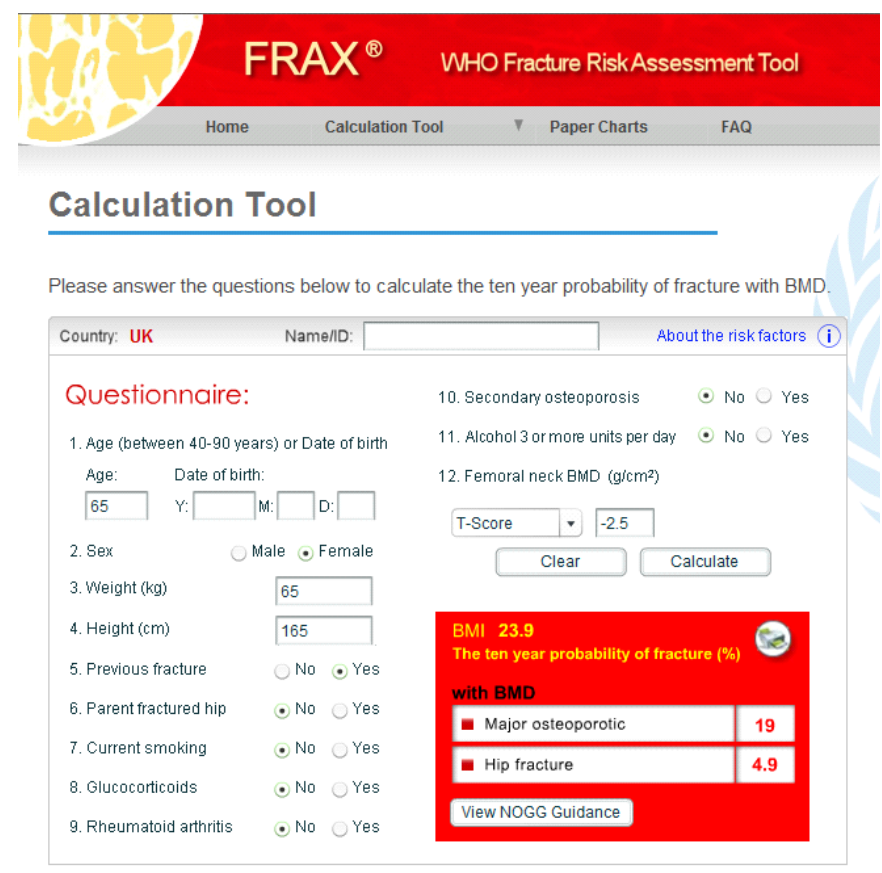

Figure. Screen page of the UK version of the $\operatorname{FRAX}^{\circledR}$ tool. 
With the introduction of FRAX, the clinical decision making has undergone major changes. Before the introduction of FRAX, DXA reports mostly indicated the diagnostic category; osteoporosis, osteopenia or normal of the patient with a rough assessment of future fracture risk. With the introduction of FRAX, apart from the diagnostic category, DXA reports now include the FRAX based 10 year fracture probability figures. This would help clinician making treatment decisions.

The fracture probability thresholds that should be adapted to make treatment decisions vary in different populations. This would depend on many factors such as cost of treatment, the willingness to pay, reimbursement policies etc, most are country specific. The National Osteoporosis Foundation in the USA recommends treating all postmenopausal women with T-score less than -2.5 and those with osteopenia and major osteoporotic fracture probability exceeding $20 \%$ or hip fracture probability exceeding 3\% estimated based on the US Caucasian FRAX model (http://www.nof.org/professionals/clinicalguidelines.) These values, however, would not be valid for a country with lower fracture incidence and where generic bisphosphonates are available to treat high risk women.

\section{Drug treatment}

Although many therapeutic options are available to treat women with osteoporosis and a high fracture risk, bisphosphonates are the most used therapeutic agent (23). Apart from their anti-fracture efficacy, these drugs are affordable and relatively safe. While alendronate and risedronate are the main oral bisphosphonates used in Sri Lanka, zoledronic acid is becoming popular. The inconvenience of injections and prohibitive cost make teriparatide a reserve drug to treat osteoporosis.

Unwanted effects and drug compliance are the major practical issues involved with long-term bisphosphonate use. Upper gastro-intestinal adverse events associated with oral bisphosphonates are the most common side effects seen among patients. The concurrent use of NSAIDs enhances the upper GI side effects. Myalgia, bone pain and arthralgia are the other common unwanted effects of oral bisphosphonates. Although they can be treated, adequately, with simple analgesics in most of the cases, symptoms can be severe enough to result in discontinuation of oral bisphosphonates in some people.

\section{Summary}

Based on the predictions of future facture occurrence, health care and social care systems in Sri Lanka will have to face an enormous burden in providing the necessary care for fracture patients. The need of preventive programs which would lessen the future fracture burden is a need. Educational programs targeting opinion leaders in health at community level could be used to raise the awareness of the disease in general. Case finding and adequate treatment are the main responsibilities of clinicians.

\section{References}

1. Anonymous. Who are candidates for prevention and treatment for osteoporosis? Osteoporos 1997; 7: 1-6.

2. Gullberg B, Johnell, O, Kanis, JA. World-wide projections for hip fracture. Osteoporos 1997; 7: 407-13.

3. Cooper C, Campion, G, Melton, LJ, 3rd. Hip fractures in the elderly: a world-wide projection. Osteoporos 1992; 2: 285-9.

4. IOF (2009) The Asian Audit; Epidemiology, costs and burden of osteoporosis in Asia 2009. http://wwwiofbonehealthorg/ publications/asian-audit-2009html.

5. Cooper C, Atkinson, EJ, Jacobsen, et al. Population-based study of survival after osteoporotic fractures. Am J Epidemiol 1993; 137: 1001-5

6. Magaziner J, Simonsick, EM, Kashner, et al. Predictors of functional recovery one year following hospital discharge for hip fracture: a prospective study. J Gerontol 1990; 45 : 101-7.

7. Riggs BL, Melton, LJ, 3rd.The worldwide problem of osteoporosis: insights afforded by epidemiology. Bone 1995; 17: 505S-11S.

8. Cooper C, Atkinson, EJ, O'Fallon, et al. Incidence of clinically diagnosed vertebral fractures: a population-based study in Rochester, Minnesota, 1985-1989. J Bone Miner Res 1992; 7: 221-7.

9. Nevitt MC, Ettinger, B, Black, DM, et al. The association of radiographically detected vertebral fractures with back pain and function: a prospective study. Ann Intern Med 1998; 128: 793-800.

10. Lips P, Cooper, C, Agnusdei, D, et al. Quality of life in patients with vertebral fractures: validation of the Quality of Life Questionnaire of the European Foundation for Osteoporosis (QUALEFFO). Working Party for Quality of Life of the European Foundation for Osteoporosis. Osteoporos Int 1999; 10: 150-60.

11. Honkanen RJ, Honkanen, K, Kroger, H, et al. Risk factors for perimenopausal distal forearm fracture. Osteoporos Int 2000; 11: 265-70.

12. O’Neill TW, Felsenberg, D, Varlow, J, et al.The prevalence of vertebral deformity in european men and women: the European Vertebral Osteoporosis Study. J Bone Miner Res 1996; 11: 1010-18.

13. Jordan KM, Cooper, C. Epidemiology of osteoporosis. Best Pract Res Clin Rheumatol 2002; 16: 795-806.

14. WHO. Assessment of fracture risk and its application to screening for postmenopausal osteoporosis. Technical Report Series. 1994.

15. Holt G, Khaw, KT, Reid, DM, et al. Prevalence of osteoporotic bone mineral density at the hip in Britain differs substantially from the US over 50 years of age: implications for clinical densitometry. Br J Radiol 2002; 75: 736-42. 
16. Jarupanich T. Prevalence and risk factors associated with osteoporosis in women attending menopause clinic at Hat Yai Regional Hospital. J Med Assoc Thai 2001; 90: 865-9.

17. Cheng XG, Yang DZ, Zhou Q, et al. Age-related bone mineral density, bone loss rate, prevalence of osteoporosis, and reference database of women at multiple centres in china. $J$ Clin Densitom 2007; 10: 276-84.

18. Lekamwasam SW, Wijerathne L, Rodrigo M, et al. Prevalence of osteoporosis among postmenopausal women in Sri Lanka: a cross-sectional community study. APLAR Journal of Rheumatology 2007; 10: 234-8.

19. Ho SC, Bacon WE, Harris T, et al. Hip fracture rates in
Hong Kong and the United States, 1988 through 1989. Am J Public Health 1993; 83: 694-7.

20. Cooper C, Cole ZA, Holroyd CR, et al. Secular trends in the incidence of hip and other osteoporotic fractures. Osteoporos Int 2011 ; 22: 1277-88.

21. Limpaphayom KK, Taechakraichana, N, Jaisamrarn, U, et al. Prevalence of osteopenia and osteoporosis in Thai women. Menopause 2001; 8: 65-69.

22. Petley GW, Cotton AM, Murrills, et al. Reference ranges of bone mineral density for women in southern England: the impact of local data on the diagnosis of osteoporosis. $\mathrm{Br} J$ Radiol 1996; 69: 655-60.

23. Delmas PD. The use of bisphosphonates in the treatment of osteoporosis. Curr Opin Rheumatol 2005; 17: 462-6. 